\title{
A study on factors related to readership of scientific articles
}

AUTHORS: Tony $\mathrm{Xu}^{1}$, Shayan Khalili ${ }^{1}$, Cynthia Deng ${ }^{1}$ SCHOOL: Earl Haig Secondary School, Toronto, Canada

\section{Abstract}

This paper analyzes the relationship between the number of Twitter and Mendeley readers with the article's subject, publisher, journal, and title length. It also looks at which country has the greatest number of readers to see if researchers can garner more visibility by publishing an article relevant to issues in those countries. The purpose of this report is to help researchers improve the visibility and impact value of their research.

The data was gathered from 550,000 scientific research papers published between January 1st and July 1st of 2016. Python's built-in JSON library was used to extract the number of Twitter and Mendeley readers, as well as the article count for each factor. The correlation between readers per article and each factor was then visualized using bubble graphs, linear regression models, and scatter plots. This paper concludes that the length of the title is the strongest factor affecting readership. In particular, titles with lengths between 51 and 90 characters have the greatest number of readers. Moreover, articles relevant to issues in countries with a higher GDP have the highest overall readership. On the other hand, the publisher and the journal did not have a significant effect on readership, while the subject of the article had a moderate effect on readership.

\section{Key Words}

big data; scientific readership; bibliometrics research

\section{Introduction}

There are a lot of scientific papers being published annually - one estimate puts the count at 1.8 million [1]. In a climate with so many articles, it is difficult for researchers, especially those at the beginning of their careers, to accrue citations. Statistics compiled by the Philadelphia-based Institute for Scientific Information indicate that $55 \%$ of the papers published between 1981 and 1985 in journals indexed by the institute received no citations at all in the 5 years after they were published [2]. The aim of this research paper is to determine how researchers can garner more visibility by maximizing the amount of views on their articles. The factors studied were the articles' subject, publisher, journal, length of title, and the location of readers. While previous studies looked at citations [3-10], this paper investigated the number of views as to take into account the interest of the general public. Previous studies investigating the relationship between the title length and citations have shown conflicting results, with two studies reporting a positive correlation [9, 10], while another finding no relationship [8]. Unlike past studies with maximum sample sizes of 140,000 papers, and many studies being limited to less than 2,220 papers, this study analyzes 550,000 papers and compares five factors.

The two statistics analyzed for each factor were the number of Mendeley readers and the number of Twitter readers. Mendeley is a program created by the publisher Elsevier, and is used for managing and sharing science research papers. Mendeley is mainly used by researchers to read about research done by other scholars, and requires submission of the person's academic status when signing up for the service. Twitter, on the other hand, is a general social media website used by the public, and unlike Mendeley, is used for sharing content regarding any topic.

It is hypothesised that countries with a higher GDP per capita will have a higher readership per million people, and that articles about the most-read subjects, published by established journals and publishers, with concise titles will have the greatest number of readers.

The study is based on Altmetrics' data on scientific articles published between January 1, 2016 and July 1, 2016. This dataset consisted of 550,000 articles. It is important to note that articles missing the required data were excluded. Scatter plots were used to determine the effect the factors had on readership, linear regression models were used to measure the strength between these relationships, and bubble plots were used to measure the impact of variables.

The findings from this study will determine how researchers can expose their research to a larger audience.

\section{Materials and Methods}

Python libraries, including pandas, matplotlib, numpy, and seaborn, were used to analyze and graph the relationship between the number of readers and the GDP per capita (for the country the reader was residing in), the subject, the publisher, the journal's impact factor, and the length of the title. Python's built-in JSON library was used to extract the number of Twitter and Mendeley readers, and the number of articles for each factor from the 550,000 JSON files. 


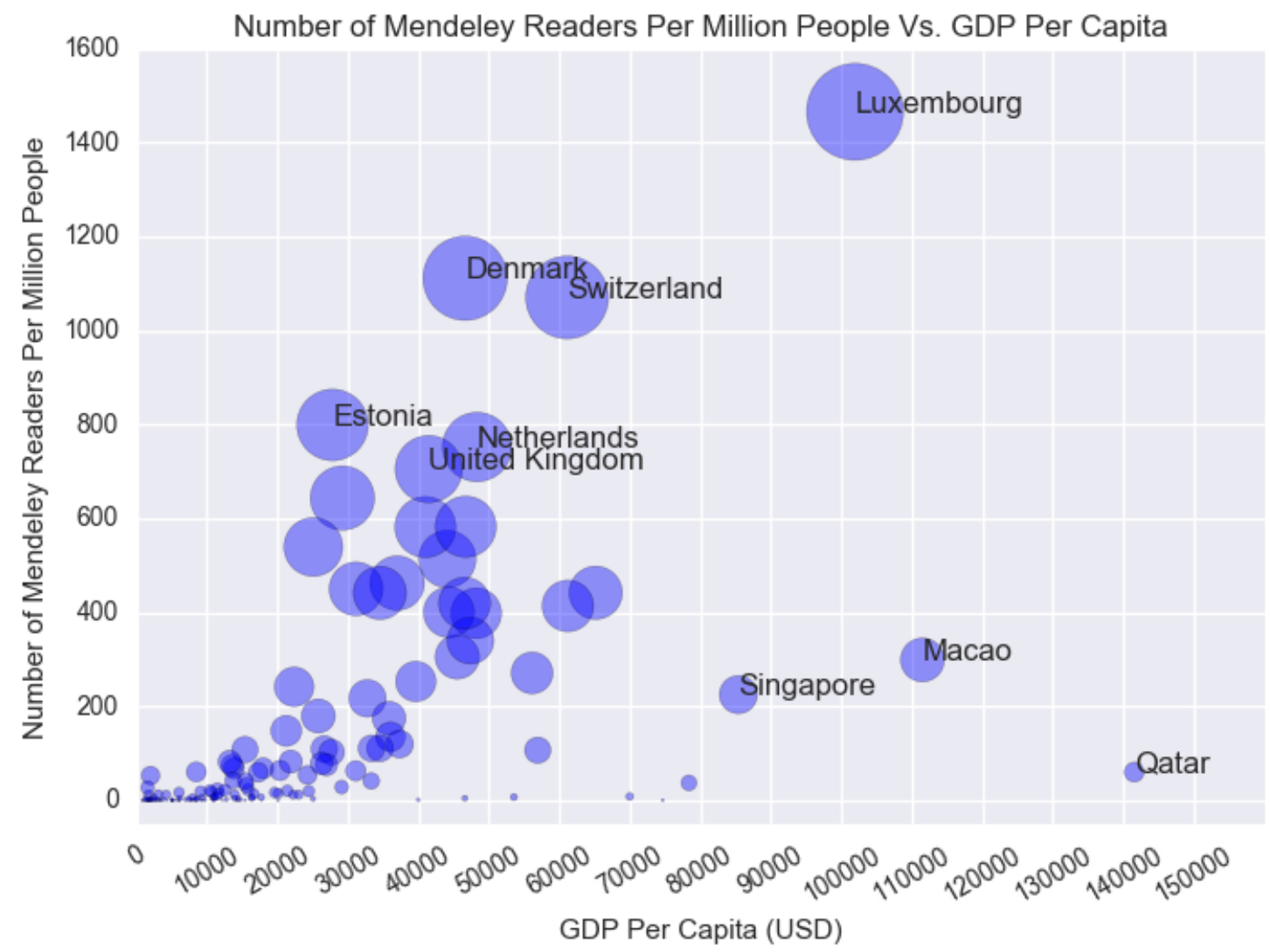

Figure 1.1: Number of Mendeley readers per million people of each country compared to the country's GDP Per Capita. Each plot represents an article. The data consists of 399313 Mendeley readers across 342068 articles. Countries without GDP or population data were excluded.

In other words, the readership and article count for each subject, publisher, journal, and character length were extracted. It is important to note that articles missing the required data were ignored. The extracted information was distributed into several data frames using pandas, each data frame corresponding to one of the factors. Matplotlib and Seaborn were used to plot the data onto scatter plots, bar graphs, and bubble plots. Numpy was used to create the linear regression line and calculate the R-squared value for the ReadersSubjects graphs. Each factor, i.e. the independent variable, was plotted against three different dependent variables: Mendeley, Twitter, and total views (Mendeley and Twitter combined).

The World Bank 2016 GDP per capita [15] and population [16] datasets were used to analyze the relationship between the number of readers in a country and the country's GDP per capita. The effect a country's GDP per capita has on the country's readership was explored using a bubble graph. The independent variable is GDP per capita, while the dependent variable is the number of readers per million people in that country. The weight and size of plots, is a visual representation of the dependant variable to highlight the views per article discrepancies between countries.

The effect the subject of an article had on its readership was investigated using a linear regression model. In Figure 2.1, the independent variable is the number of articles published on a subject and the dependent variable is the average number of readers per article of that subject. On the other hand, in Figure 2.2, the dependent variable is the total number of viewers. Each point represents a subject.

The effect that the publisher of an article has on its readership was investigated using bubble graphs in Figures 3.1 and 3.2. Each plot represents a publisher. In Figure 3.1, the independent variable is the number of articles published by that publisher. The dependent variable is the number of readers per article for a publisher, and the weight represents the percentage of the publisher's articles that covers one of the top ten most viewed subjects (most viewed in terms of readers per article).

In Figures 4.1 and 4.2, the effect the journal had on the number of readers and readers per article is investigated in the same way as the publisher-readers graphs. 


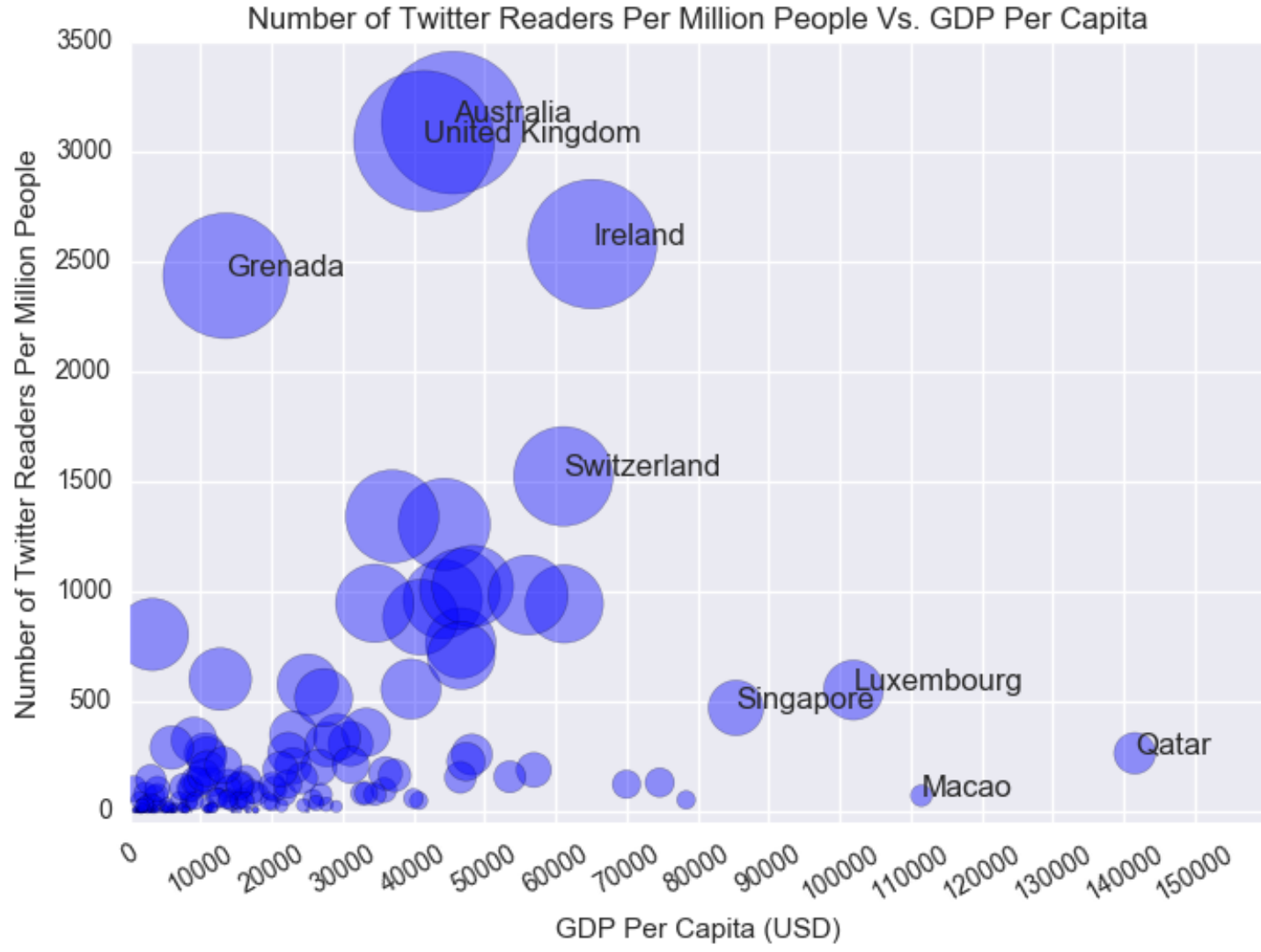

Figure 1.2: Number of Twitter readers per million people of each country compared to the country's GDP Per Capita. Each plot represents an article. The data consists of 990695 Twitter readers across 342068 articles. Countries without GDP or population data were excluded.

\section{Number of Readers Per Article for Each Subject VS. Number of Research Articles Published for Each Subject}

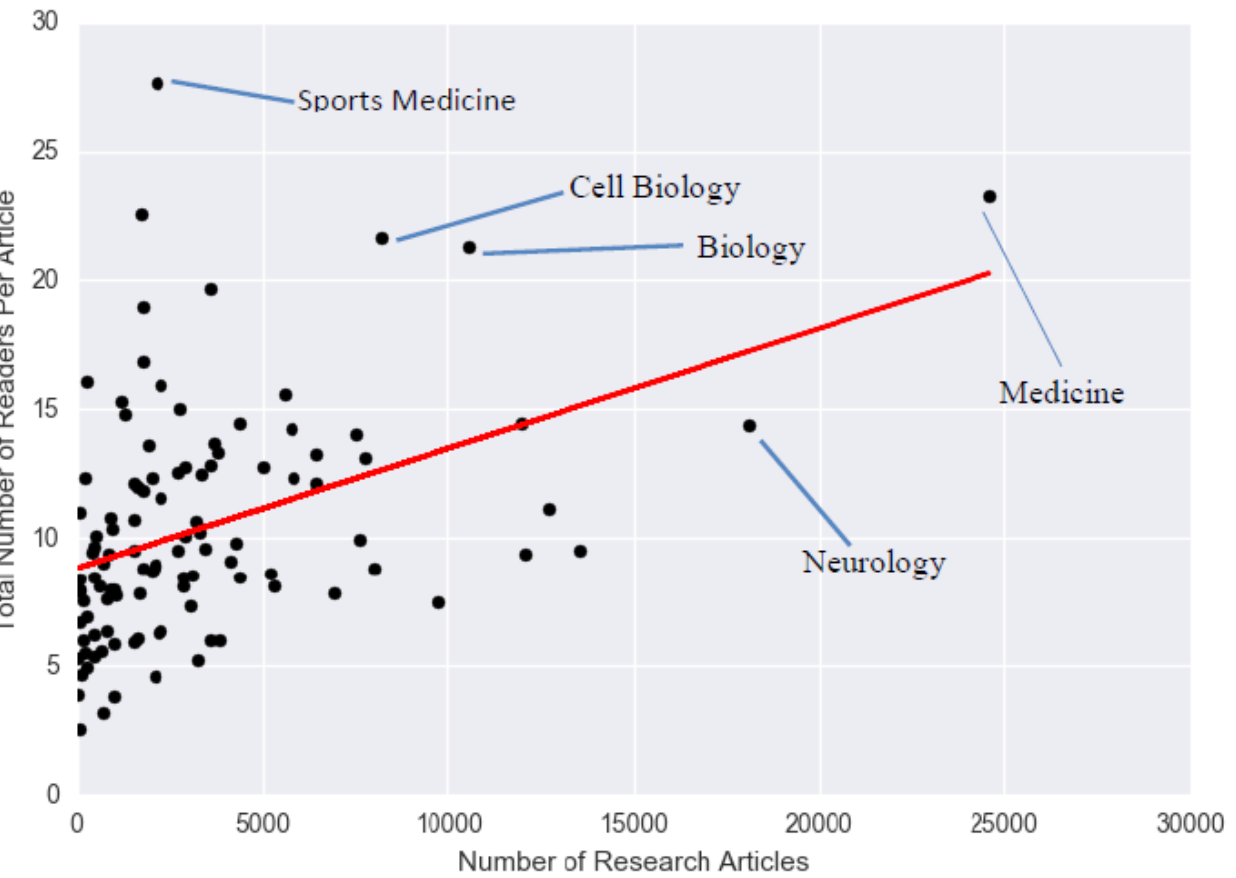

Figure 2.1: Total number of readers per article for each subject. Each plot represents an article. The data consists of 2409199 Mendeley readers and 1947371 Twitter readers across 347909 articles. ${ }^{2}$ value of 0.16 . 


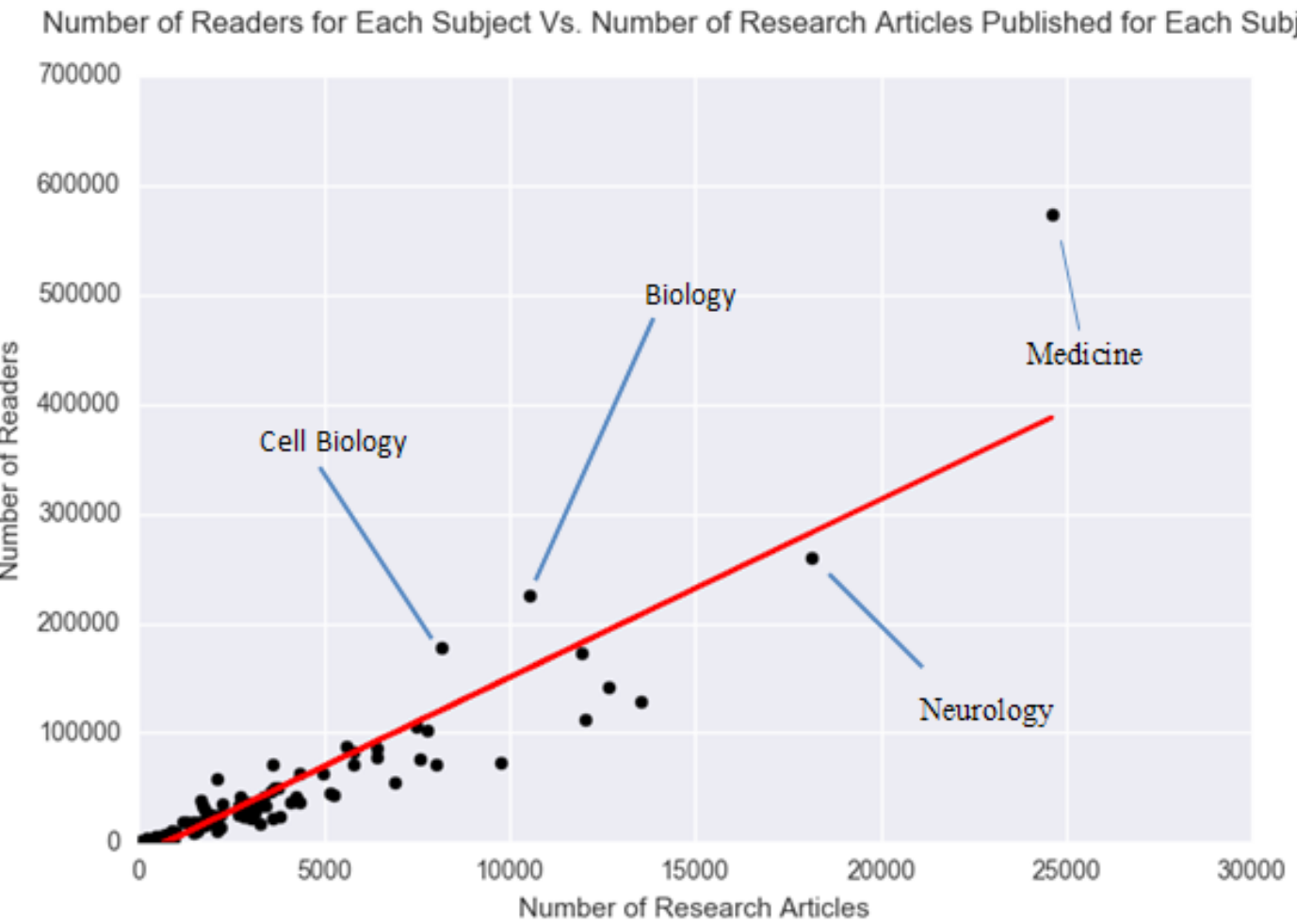

Figure 2.2: Total number of readers for each subject. Each plot represents an article. The data consists of 2409199 Mendeley readers and 1947371 Twitter readers across 347909 articles. ${ }^{2}$ value of 0.84 .

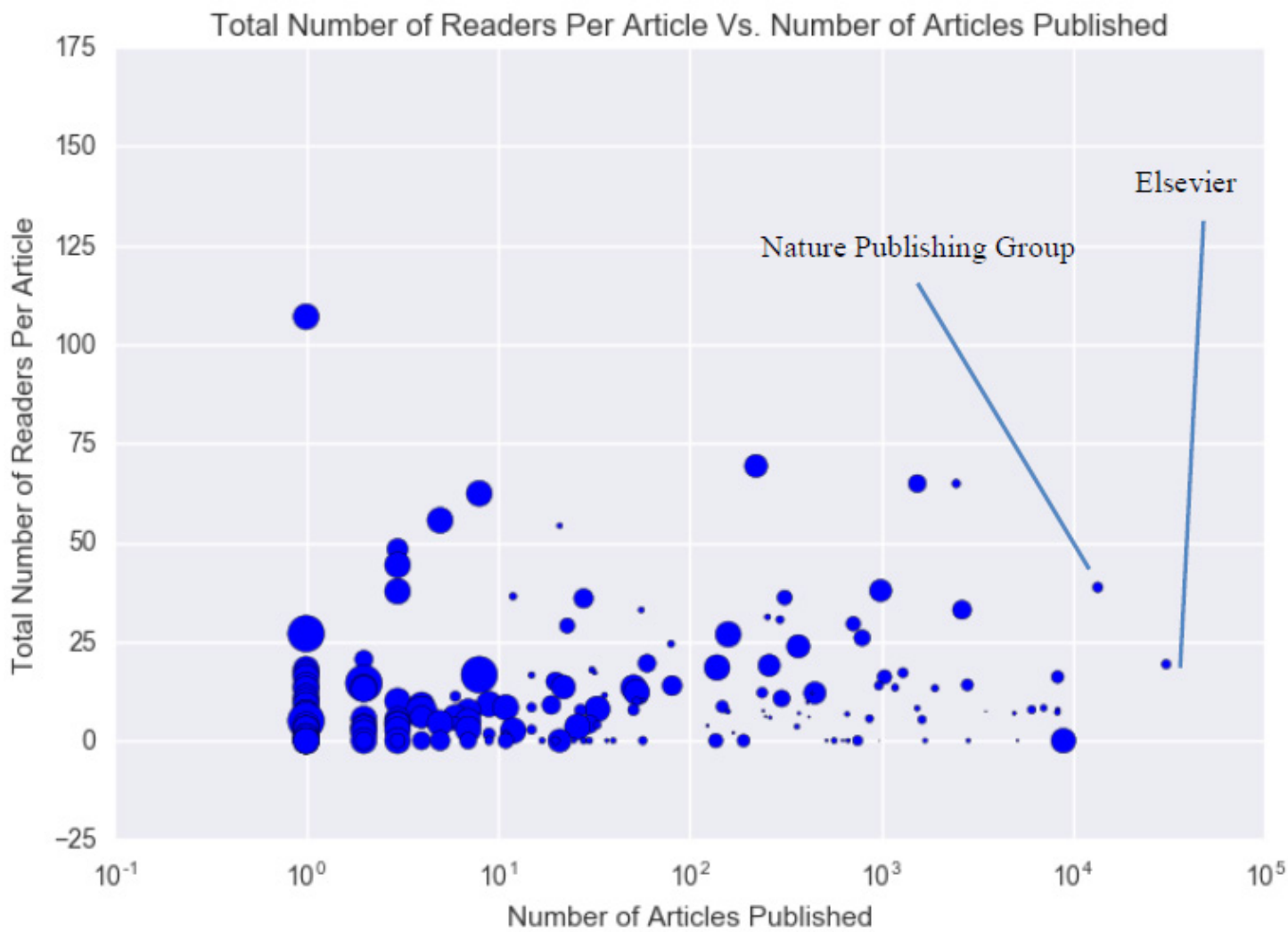

Figure 3.1: Number of readers per article for each publisher, Twitter and Mendeley combined. Each plot represents an article. The data consists of 1516753 Mendeley readers and 1537926 Twitter readers across 211949 articles. A log scale for the x-axis was used for better visual representation. The two publishers with the most articles published are labeled. 
The effect the length of an article's title had on its readership was investigated using a scatter plot. The independent variable is the character count of the title. The dependent variable is the average number of readers per article. This is calculated by dividing the total number of readers by the number of articles with the same character count in the title.

\section{Results}

There is a clear positive correlation between the GDP per capita and number of readers per million people in the GDP per capita range of 0 to 70,000 USD. Afterwards, the trend becomes insignificant, as many outliers appear.

With an R-squared value of 0.84 , Figure 2.2 shows a strong positive linear relationship between the total number of readers of a subject and the number of research articles published on that subject. However, Figure 2.1 shows a weak positive linear relationship between the number of readers per article and the number of research articles published on that topic. Figure 2.1 has an R-squared value of 0.16 , which indicates that the research topic does not have a clear relationship with the popularity of the article.

In both Figures 3.1 and 3.2, each point represents a publisher.
Figure 3.1 plots the total number of readers per article (Mendeley and Twitter combined) against the number of articles published by the respective publisher. Figure 3.2 plots the total number of readers (not per article) against the number of articles published by the respective publisher. The weight (size of the circles) represents the percentage of the articles by the respective publisher covering one of the ten most viewed subjects, shown in the following table.

There is no clear correlation between the number of articles published and the number of readers per article. However, as the number of articles increases, the percentage of articles covering one of the top ten most read subjects decreases.

In Figure 4.1 and 4.2, each plot represents a journal. Figure 4.2 plots the total number of readers per article (Mendeley and Twitter combined) against the number of articles published by the respective journal. Figure 4.1 plots the total number of readers (not per article) against the number of articles published by the journal. The weight (size of the circles) represents the percentage of the articles published by the journal covering at least one of the ten most viewed subjects.

There is no relationship between the number of readers per article and the journal in which the article is published in. Moreover,

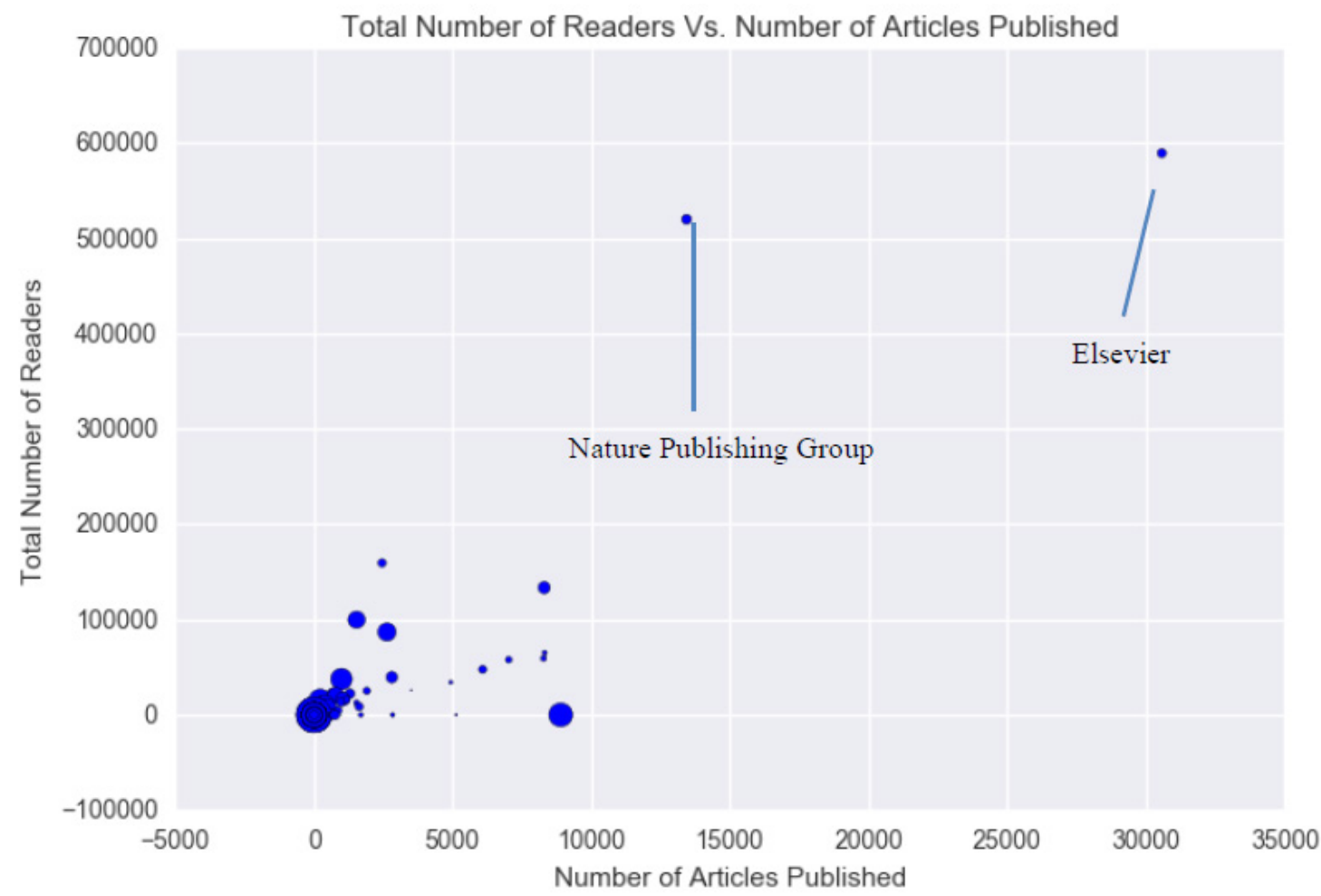

Figure 3.2: Total number of readers for each publisher, Twitter and Mendeley combined. Each plot represents an article. The data consists of 1516753 Mendeley readers and 1537926 Twitter readers across 211949 articles. The two publishers with the most views and articles published are labeled. 


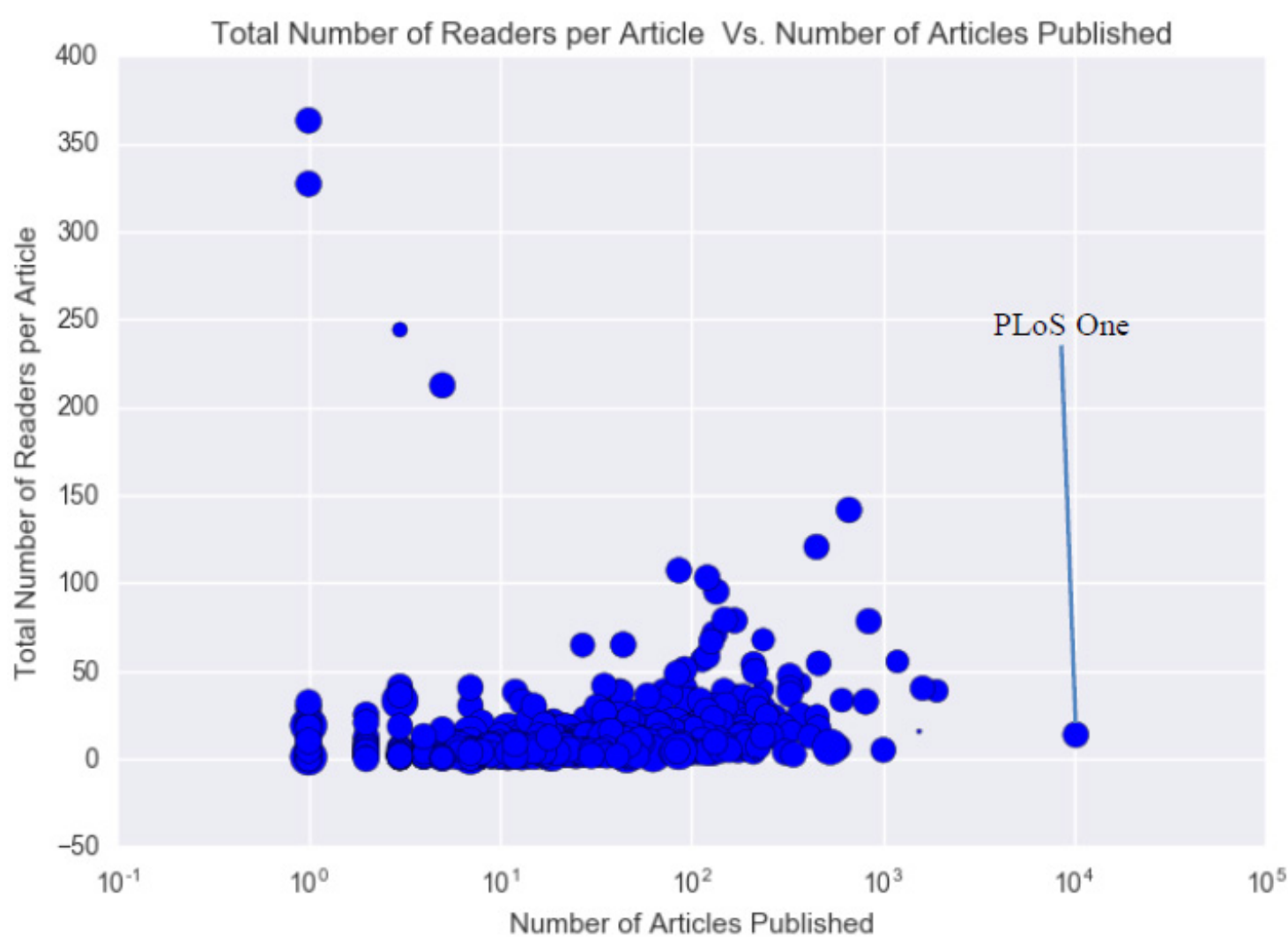

Figure 4.1: Number of readers per article for each journal, Twitter and Mendeley combined. Each plot represents an article. The weight (size of the circle) is the percentage of articles published in the top 10 subjects with the most views per article. The data consists of 3225 233 Mendeley readers and 3699002 Twitter readers across 504217 articles. A log scale was used for the x-axis for better visual representation. The journal with the most articles published is labeled.

it seems that every journal contains an equal percentage of articles covering the top ten most viewed subjects.

Titles with a length of 61 to 100 characters have the highest number of Mendeley readers. Titles with a length between 41 and 80 characters have the highest number of Twitter readers. Twitter readership peaks at a shorter title length (around 40 characters), and has more average readers per article in the 0 to 80 characters range. There is a drastic decrease in readership up until 100 characters, before continuing to decrease at a more linear rate after 100 characters. Mendeley readers peak at around 80 characters and gradually decrease after the peak. Twitter also draws a higher count of total readers than Mendeley.

\section{Discussion}

Figures 1.1 and 1.2 display a strong relationship between the GDP per capita and the number of readers per million people, indicating residents of countries with a higher GDP per capita read more science papers. Many of the outliers represent countries that have a high GDP per capita, but are less developed in other areas
$[14,15]$. A source of error is that Mendeley readers are mostly Anglophonic, and this is demonstrated by the near absence of nonEnglish articles, the plethora of complaints on Mendeley language support [19-23], and the lack of a translation feature. Similarly, the majority of Twitter users are from English-speaking countries [24, 25] partly because the platform is banned in countries (e.g. China), and falls behind competing social networks in such countries, resulting in an intrinsic bias in our dataset.

Although Figure 2.2 shows that research topics with more articles have a greater total number of readers, Figure 2.1 shows that they do not have a conclusive effect on the readership per article. Since research is funded by private corporations, foundations, and governments, it can be hypothesized that there will be more articles published on subjects affecting a greater number of people. For example, although sports medicine has one of the highest numbers of readers per article, there is limited of research on it because it has a low total number of readers. In other words, a minority of the population is interested in sports medicine. As a result, there are not a lot of articles published on sports medicine, because it would be 


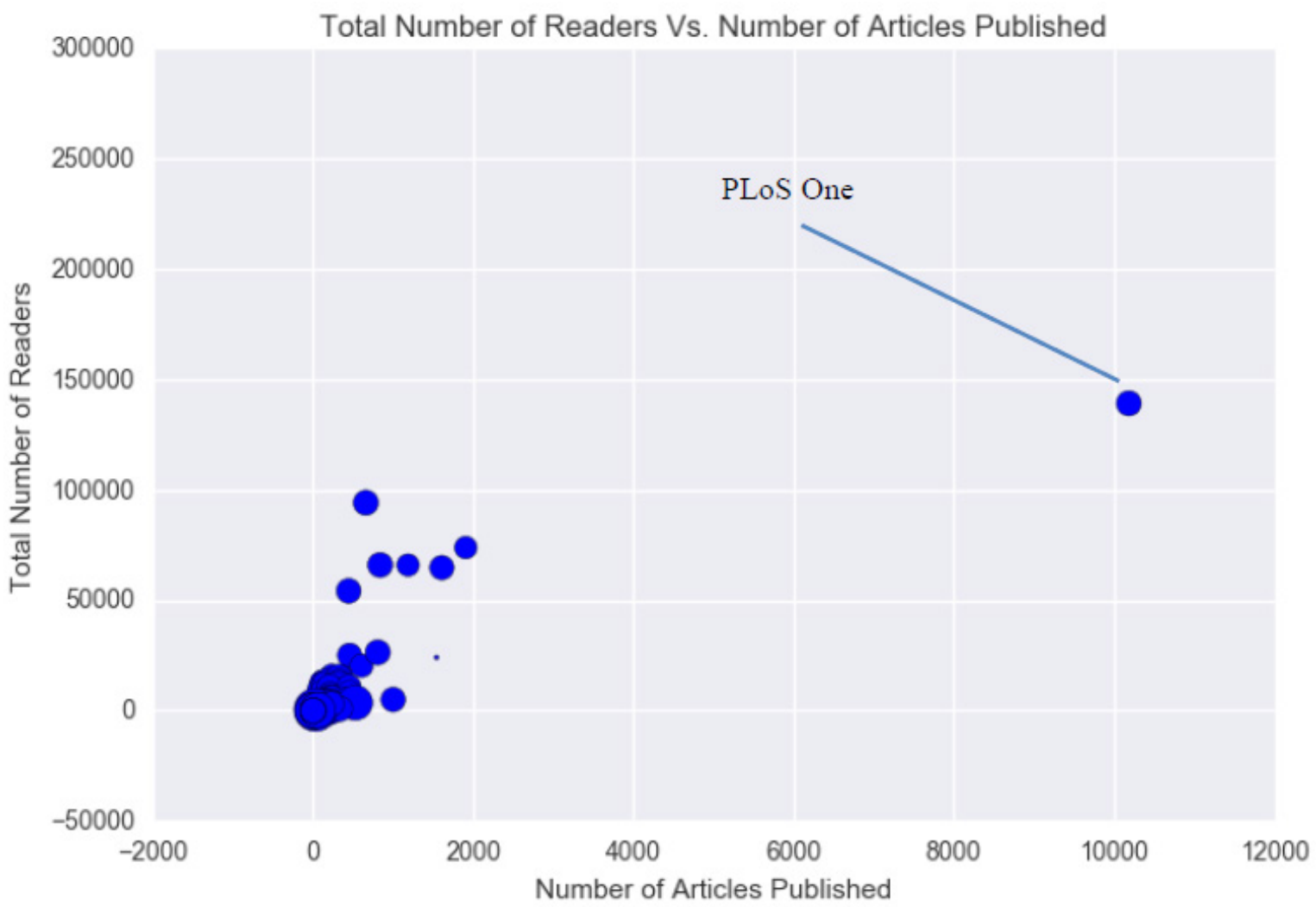

Figure 4.2: Total number of readers for each journal, Twitter and Mendeley combined. Each plot represents an article. The weight (size of the circle) is the percentage of articles published in the top 10 subjects with the most views per article. The data consists of 3225233 Mendeley readers and 3699002 Twitter readers across 504217 articles. The journal with the most views and articles published is labeled.

more profitable for corporations and beneficial to governments to fund research impacting the general populace.

It is noteworthy that Twitter readers are more interested in medicine than Mendeley readers, while Mendeley readers are more interested in biology and cell biology. This is reflected in Figures 2.3 and 2.4, as well as 2.5 and 2.6 (appendices). This is because Twitter is used by the general populace, so it can be hypothesized that Twitter users are more prone to reading articles about topics that can personally affect them. Twitter users are also more likely to be casually scrolling through the platform. On the other hand, biology and cell biology are popular among Mendeley readers, because Mendeley is a platform for health science researchers and doctors. Consequently, Mendeley readers will likely be looking specifically for research done in their field. In general, Twitter users are more interested in topics that influence their daily lives, while Mendeley readers are more interested in their specific fields (such as biology and cell biology).

Figure 3.1 concludes that articles from major publishers will not lead to more readers per article. The reason that publishers with fewer articles published have a higher percentage of articles published in the ten most viewed subjects is likely because they are niche journals. When the total number of readers is plotted against the number of articles (Figure 3.2), there is a significant difference in the total number of readers between the top two publishers (Elsevier and Nature) and the other publishers. As a result, it can be inferred that a duopoly exists between the Elsevier and Nature Publishing Groups.

Similar to publishers, the journal itself does not affect readership per article (Figure 4.1). Furthermore, similar to Elsevier and Nature Publishing Group, PLoS One publishes a significantly larger number of articles than its competitors (Figure 4.2). However, unlike publishers, the number of articles in a journal does not significantly affect the total number of readers (figure 4.2).

When comparing the two in Figure 5.2, Twitter readership peaks at a shorter title length than Mendeley. Our proposed explanation for this result is that Twitter readers are not specifically looking for scientific articles. Instead, they are most likely browsing through miscellaneous tweets, thus, they are more likely to be scrolling at 
Number of Twitter and Mendeley Readers VS. Number of Characters in Title

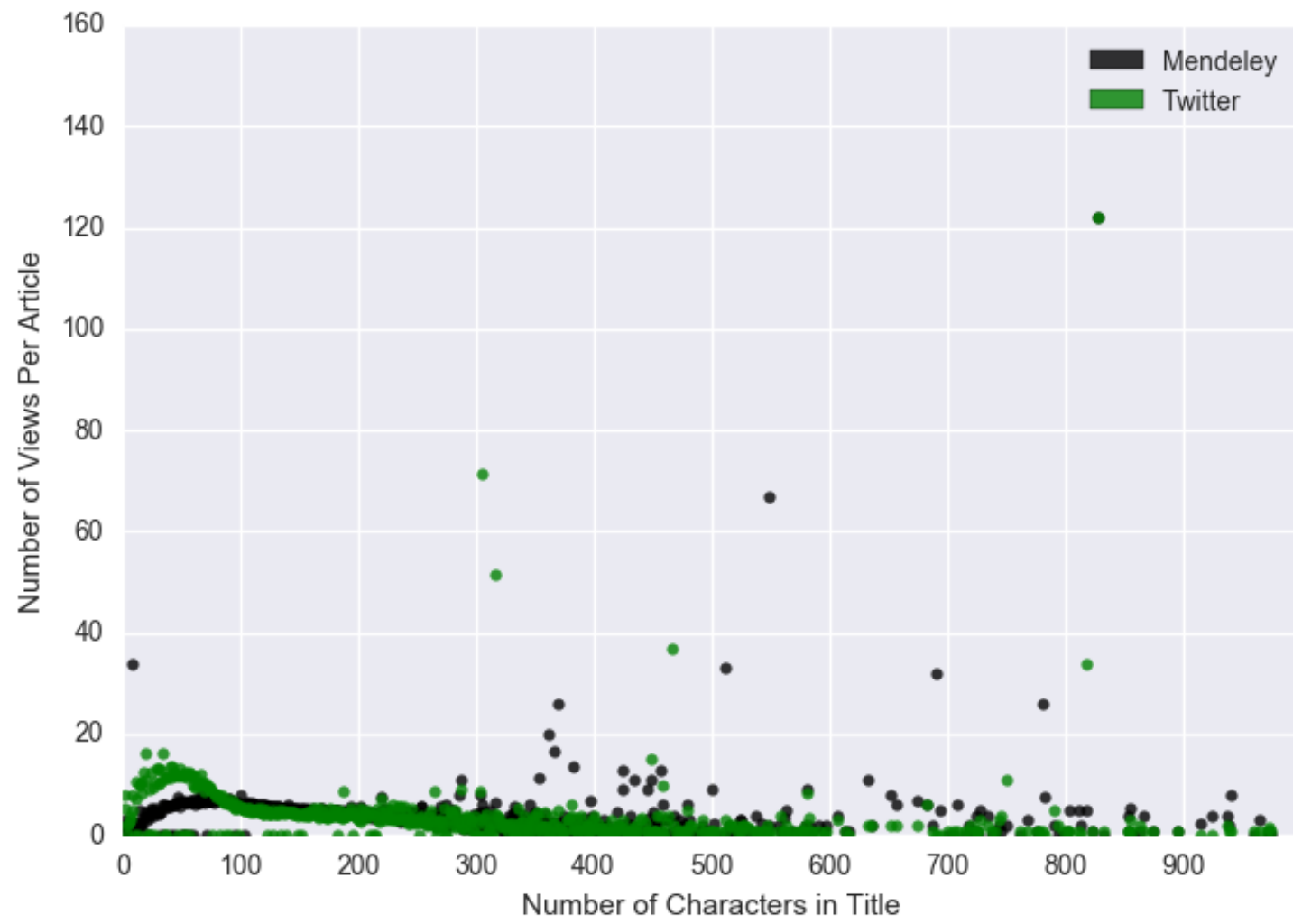

Figure 5.1: The number of readers for Twitter and Mendeley for each title length from 1 to 1000 characters. Each plot represents an article. The data consists of 3018512 Mendeley readers and 3385999 readers across 536573 articles. Title lengths beyond 1000 characters were excluded because they had very little views.

Table1: A table of the ten most viewed subjects.

\begin{tabular}{|c|c|c|}
\hline & Subject & Total Readers \\
\hline 1 & Medicine & 574,238 \\
\hline 2 & Neurology & 260,696 \\
\hline 3 & Biology & 225,241 \\
\hline 4 & Cell Biology & 177,574 \\
\hline 5 & Molecular Biology & 172,591 \\
\hline 6 & Chemistry & 141,428 \\
\hline 7 & Neoplasm & 129,057 \\
\hline 8 & Biochemistry & 112,798 \\
\hline 9 & Environmental Health & 105,467 \\
\hline 10 & Psychiatry & 101,576 \\
\hline
\end{tabular}




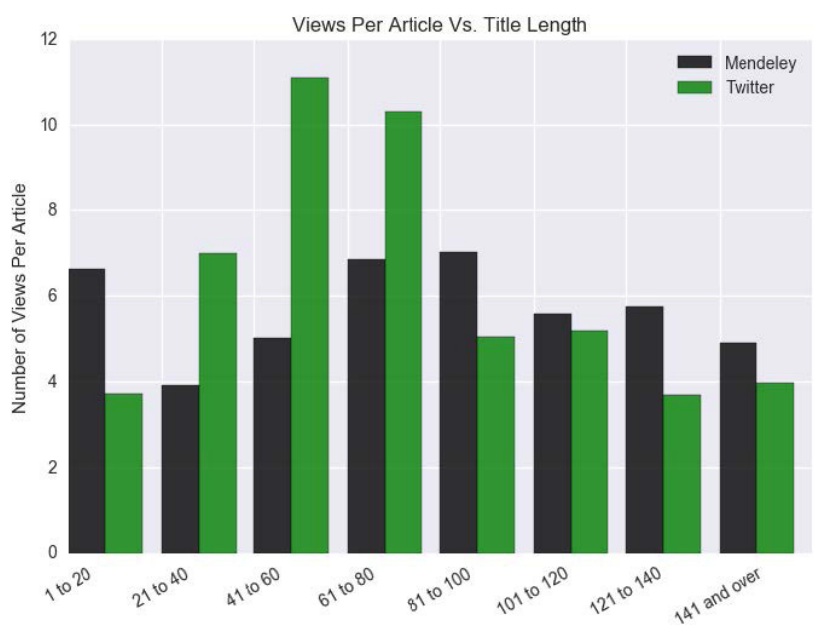

Number of Characters in Title

a higher rate. As a result, they are more likely to scroll past articles that do not have concise titles. Moreover, Twitter has a maximum post length of 140 characters, and when adding an article, only around 50 to 60 characters are shown in the preview. Thus, if the title of the article fails to catch the reader's attention in 50 or 60 characters, Twitter users will skip over the tweet. On the other hand, Mendeley users gravitate towards more detailed titles because they are looking for articles on a specific subject. The outliers can be explained by the way the readership per article was calculated. It was found by dividing the total number of readers (of a certain title length) by the number of articles. Consequently, if a particular title length has a small number of articles, but has one article with a lot of readers, the average readers per article is skewed for that title length.

It should also be noted that there is also bias inherent in the combined Twitter and Mendeley graphs, as the number of Mendeley views were not equal to the number of Twitter views.

Previous studies have found that papers in particular academic domains are correlated with more citations [11] and reported conflicting results on the relationship between citations and title length [8-10], as well as with publishing in higher-impact journals $[12,13]$. Our study finds that particular academic domains and concise titles are correlated with more views (Figure 2.1), while journals have minimal correlation with readership.

\section{Conclusion}

The strongest factor affecting readership is the character length of the title. From Figure 5.2, it can be concluded that articles pub-
Figure 5.2: The average number of readers for Twitter and Mendeley for 7 ranges of title lengths starting from 1 character and going up to 140 characters, incrementing by 20 characters for each group. The last group is the average of all readers for title lengths of 141 characters and beyond. The data consists of 3018512 Mendeley readers and 3385999 readers across 536573 articles. lished with title lengths between 61 to 100 characters have the greatest number of Mendeley views, while title lengths between 41 to 80 characters have the greatest number of Twitter readers. On the other hand, the publisher and journal did not have a significant effect on readership per article. Thus, being published by established publishers or journals is not an important factor in maximizing views. Moreover, articles published on sports medicine, biology, cell biology, and computational biology have significantly more readers per article than any other subject. Similarly, the comparison between the number of readers per million people in a country, and the GDP per capita of a country, indicated that countries with a higher GDP per capita generally read more scientific articles. Therefore, it can be extrapolated that articles addressing how their respective topic impacts citizens in developed countries will have more readers.

Future studies should track these factors over several years to see if the current trend persists. More importantly, future studies should take into account non-English scientific studies and researchsharing platforms in order to remove the intrinsic bias towards the interests and reading habits of English-speaking countries.

\section{Acknowledgement}

We would like to extend our sincerest thanks and appreciations to all those who helped made this challenge a possibility. We would like to recognize Mr. Jay Rajasekharan and Dr. Sacha Noukhovitch for their guidance and encouragement. We especially appreciate Mr. Rajasekharan's background knowledge, patience, and dedication in guiding us through this project. 


\section{REVIEW}

\section{by Dr. Anna Mkrtchyan \\ PhD in Computational Biophysics}

In this paper authors investigate factors that could potentially contribute to the visibility of research articles. Traditionally, article citations are used as an indicator of its impact on scientific community. Here, authors use Mendeley reads and Twitter posts as the measure of the engagement of general public with research. They analyze the relationship between number of Mendeley reads and Twitter posts and several factors, namely, article's subject, the length of its title, the publisher, and the journal. They also look into the effect of country's GDP per capita on country's readership. Authors use visualization techniques and linear regression in their analysis.

Methodology is explained clearly and in detail, and relevant statistics are reported. For reproducibility purposes, authors should expand more on all data sources they use and how they extract relevant statistics. For example, aside from Altmetric, other open data sources such as WorldBank appear in references but are not discussed in the main text.

Results are discussed in great detail. Possible error sources are also highlighted. Authors offered various hypotheses as to what could cause a given outcome in the paper. Plausible explanations for the observations are well-thought and make sense. However, authors should be careful in distinguishing their hypothesis from known facts. Latter should be backed up by proper citations.

This paper would greatly benefit from editing and formatting. For example, the way that the views per article are calculated should be described in Methods section rather than Discussion. All figures should be properly referenced. Supplementary figures should have proper captions as well. There are typos that, in some cases, alter the meaning of the text/figures. Nevertheless, this is certainly an interesting paper with a lot of potential. Students did a great job in the attempt to isolate factors that contribute to readership of research articles.

\section{References}

1. Ware M, Mabe M. The stm report: An overview of scientific and scholarly journal publishing. International Association of Scientific, Technical and Medical Publishers [Internet]. 2012 Nov. Available from: http://www. stm-assoc.org/2012_12_11_STM_Report_2012.pdf

2. Pendlebury DA. Science, Citation, and Funding. Science. 1991; 251:1410-1411.

3. Yogatama D, Heilman M, O'Connor B, Dyer C, Routledge BR, Smith NA. Predicting a scientific community's response to an article. Proc. EMNLP. 2011 July; 594-604.

4. Soler V. Writing titles in science: an exploratory study. J. Exp. Soc. Psychol. 2007; 26:90-102.

5. Lewison G, Hartley J. What's in a title? Numbers of words and the presence of colons. Scientometrics. 2005; 63:341-356.

6. Hartley J. To attract or to inform: what are titles for? JTWC. 2005; 35:203-123.

7. Hartley J. Planning that title: practices and preferences for titles with colons in academic articles. Libr. Inf. Sci. Res. 2007; 29:553-568.

8. Jamali HR, Nikzad M. Article title type and its relation with the number of downloads and citations. Scientometrics. 2011; 88:653-661.

9. Jacques TS, Sebire NJ. The impact of article titles on citation hits: an analysis of general and specialist medical journals. J. R. Soc. Med. Short Rep. 2009; 1:1-5.

10. Letchford A, Moat HS, Preis T. The advantage of short paper titles [Internet]. Open Science. The Royal Society; 2015 [cited 2017 Jun 22]. Available from: http://rsos.royalsocietypublishing.org/content/2/8/150266\#ref-41 11. Yogatama D, Heilman M, O'Connor B, Dyer C, Routledge BR, Smith NA. Predicting a scientific community's response to an article. Proc. EMNLP. 2011 July; 594-604.

12. Lariviere V, Gingras $Y$. The impact factor's Matthew effect: a natural experiment in bibliometrics. J. Am. Soc. Inf. Sci. Tech., 2010; 61: 424-427 13. Lariviere V, Kiermer V, MacCallum CJ, McNutt C, Patterson M, Pulverer B, Swaminathan S, Taylor S, Curry S. A simple proposal for the publication of journal citation distributions. bioRxiv. 2016. Available from: https://doi.org/10.1101/062109

14. Altmetric Explorer. (n.d.). Retrieved January 15, 2017, from https:// www.altmetric.com/explorer/outputs

15. GDP per capita (current US\$). (n.d.). Retrieved January 15, 2017, from http://data.worldbank.org/indicator/NY.GDP.PCAP.CD

16. Population, total. (n.d.). Retrieved January 15, 2017, from http://data. worldbank.org/indicator/SP.POP.TOTL

17. Singapore. (2016, December). Retrieved January 15, 2017, from http:// www.forbes.com/places/singapore/

18. Qatar. (2016, December). Retrieved January 15, 2017, from http:// www.forbes.com/places/qatar/

19. Mendeley Forum: Translation-feature. 2011, March 2. Retrieved August 29, 2017, from https://mendeley.uservoice.com/forums/4941-general/ suggestions/1547193-translation-feature

20. Mendeley Forum: Better support for Asian characters like Chinese and Japanese. 2009, November 2. Retrieved August 29, 2017, from https:// mendeley.uservoice.com/forums/4941-general/suggestions/371755-bettersupport-for-asian-characters-like-chinese-a

21. Mendeley Forum: Spanish versions. 2016, April 24. Retrieved August 29, 2017, from https://mendeley.uservoice.com/forums/4941-general/ suggestions/13572216-some-version-of-mendeley-in-spanish

22. Mendeley Forum: Russian interface for Mendeley. 2015, January 15. Retrieved August 29, 2017, from http://mendeley.uservoice.com/ forums/4941-general/suggestions/6965962-russian-interface-for-mendeley 23. Mendeley Forum: Add Google Translate. (2013, September 12). Retrieved August 29, 2017, from https://mendeley.uservoice.com/ forums/4941-general/suggestions/4421832-add-google-translate-in-yourdefine-feature

24. Countries with most Twitter users 2016 I Statistic. (2016). Retrieved August 29, 2017, from https://www.statista.com/statistics/242606/numberof-active-twitter-users-in-selected-countries/

25. Twitter: most-used languages 2013 I Statistic. (2013). Retrieved August 29, 2017, from https://www.statista.com/statistics/267129/most-usedlanguages-on-twitter/ 


\section{Appendix}

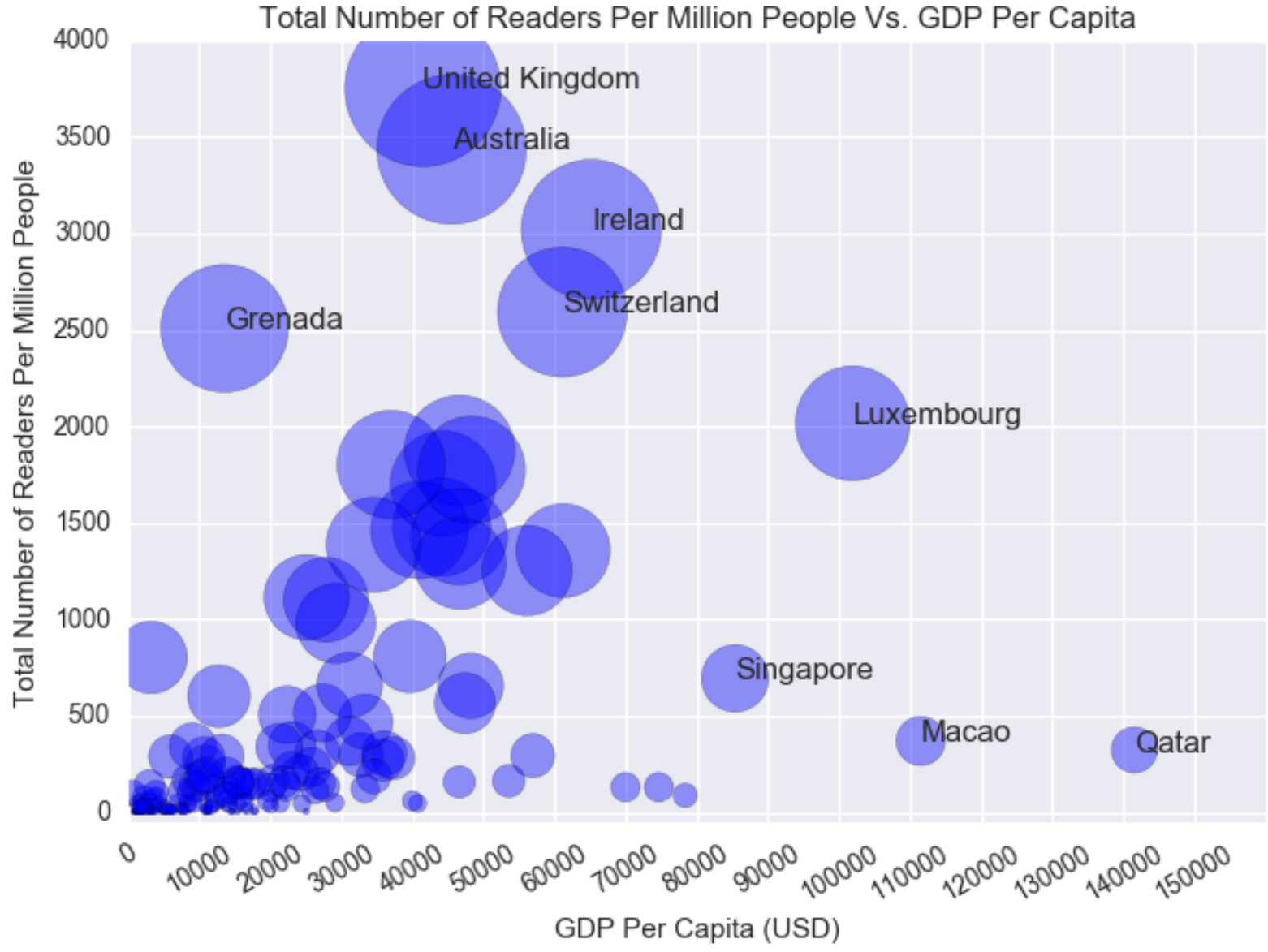

Figure 1.3: This bubble graphs shows the relationship between the total number of readers (Twitter and Mendeley) per million people and the GDP per capita of a country. The weight is a visual representation of the $y$-axis. The data consists of 399313 Mendeley readers and 990695 Twitter readers across 342068 articles.

Number of Mendeley Readers Per Article for Each Subject VS. Number of Research Articles Published for Each Subject

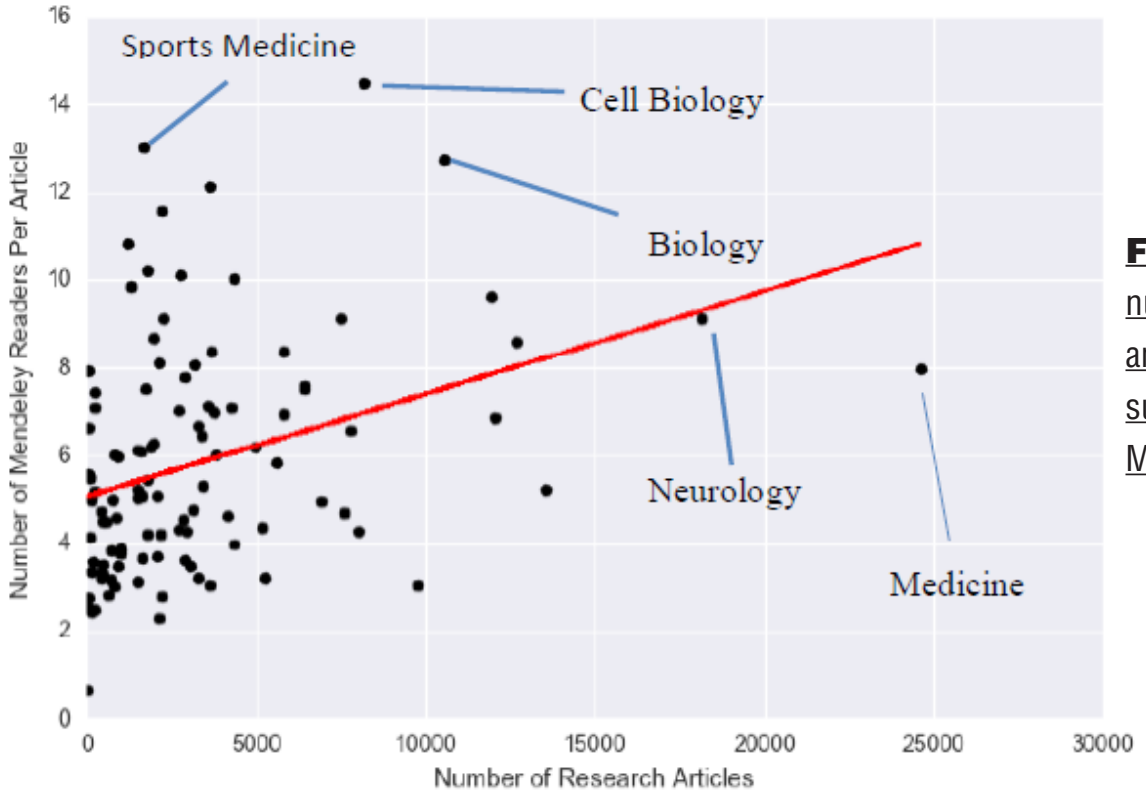

Figure 2.3: Relationship between number of Mendeley readers per article and subject. Each plot represents a subject. The data consists of 2409199 Mendeley readers across 347909 articles. 
Number of Twitter Readers Per Article for Each Subject VS. Number of Research Articles Published for Each Subject

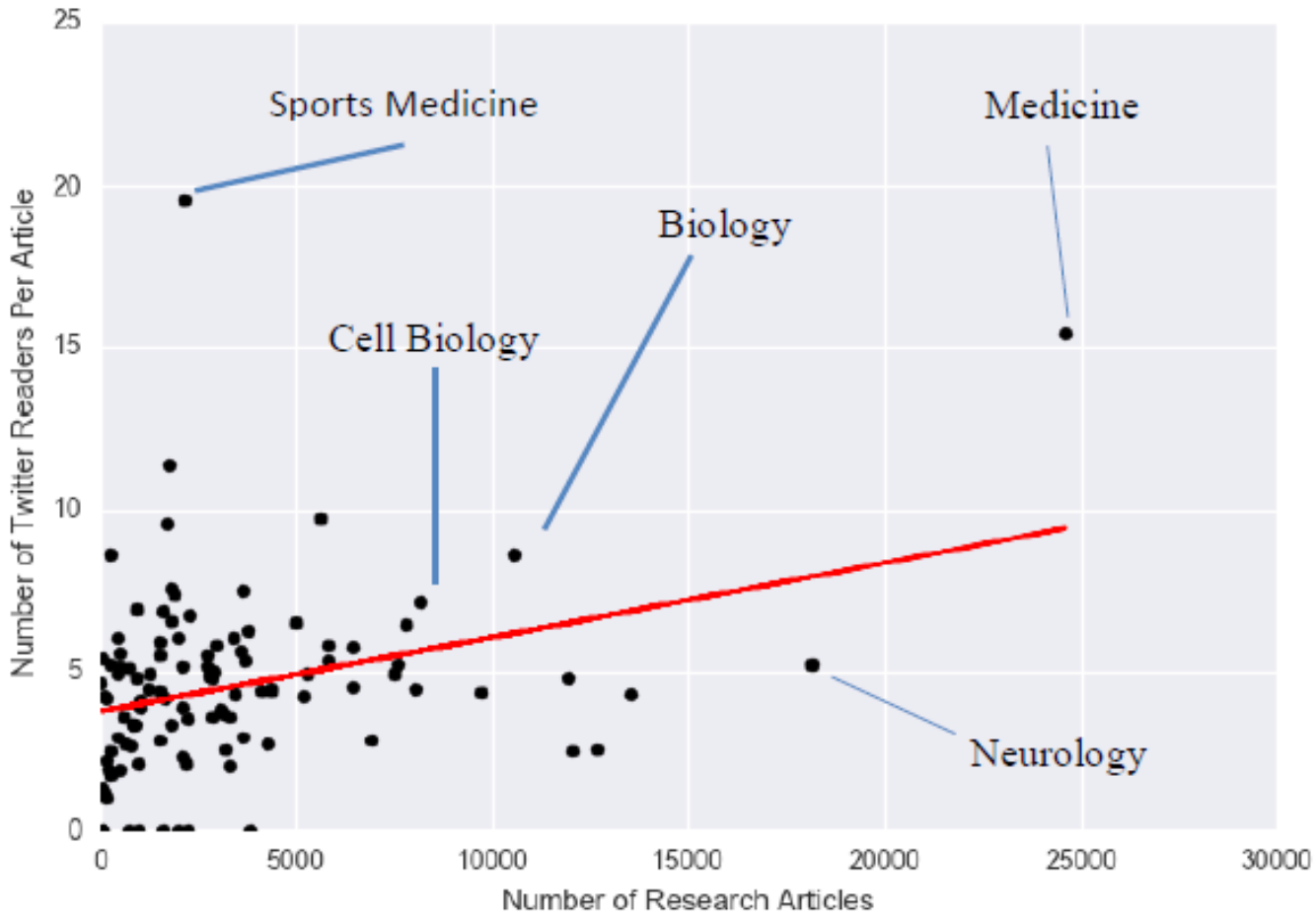

Figure 2.4: Relationship between number of Twitter readers per article and subject. Each plot represents a subject. The data consists of 1947371 Twitter readers across 347909 articles.

Number of Mendeley Readers for Each Subject VS. Number of Research Articles Published for Each Subject 250000

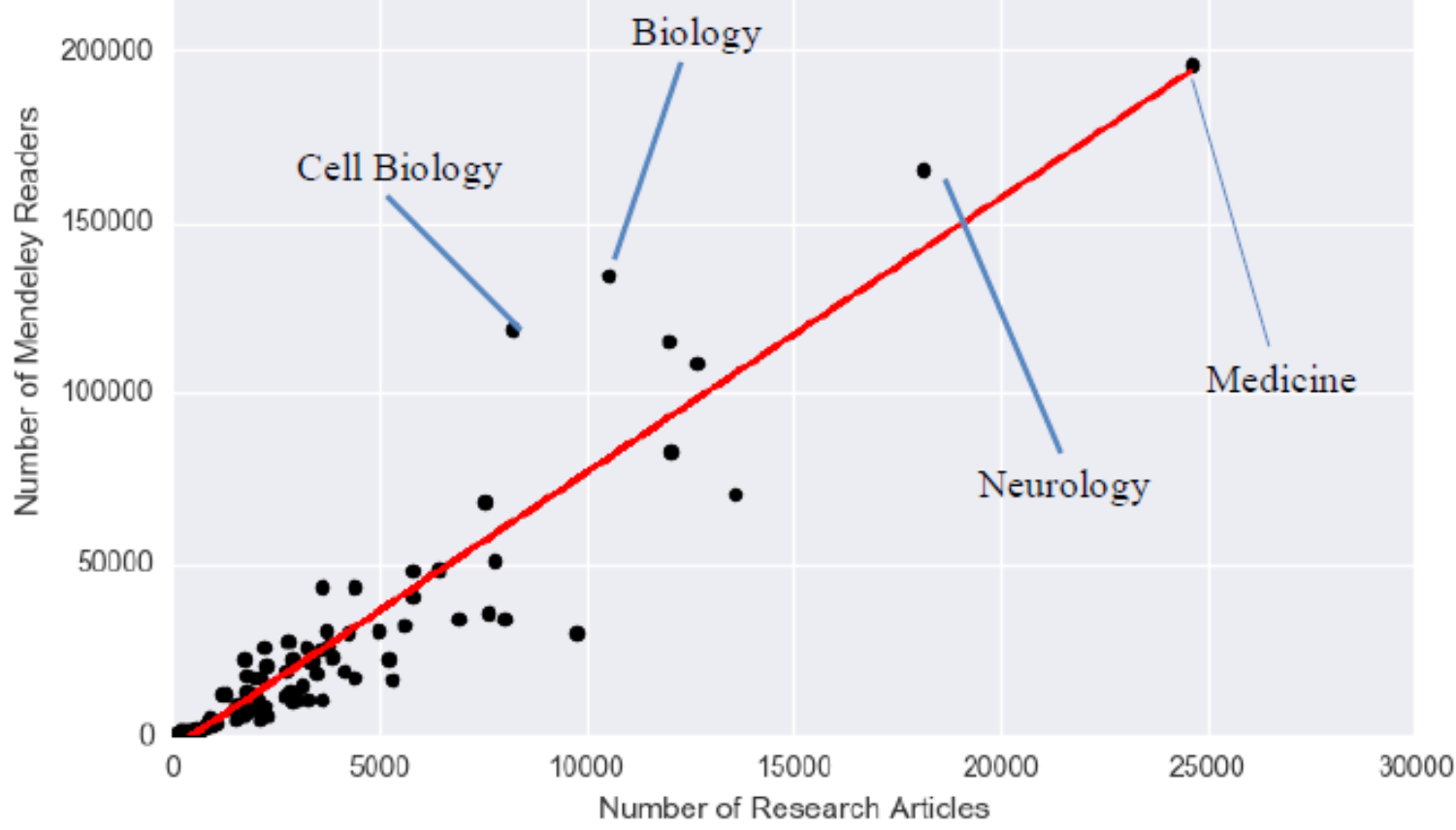

Figure 2.5: Relationship between total number of Mendeley readers and subject. Each plot represents a subject. The data consists of 2 409199 Mendeley readers across 347909 articles. 
Number of Twitter Readers for Each Subject VS. Number of Research Articles Published for Each Subject 400000

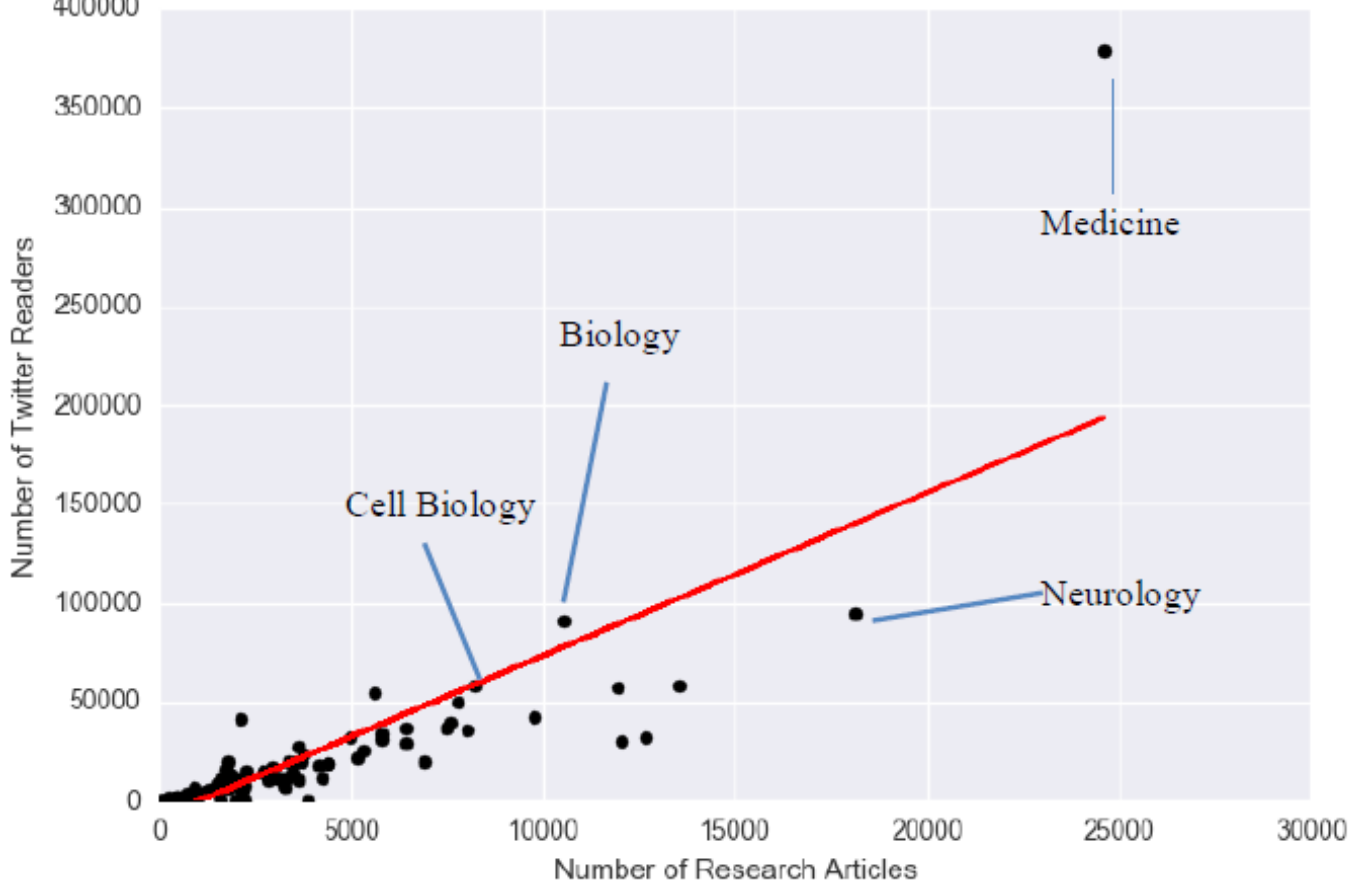

Figure 2.6: Relationship between total number of Twitter readers and subject. Each plot represents a subject. The data consists of 1 947371 Twitter readers across 347909 articles.

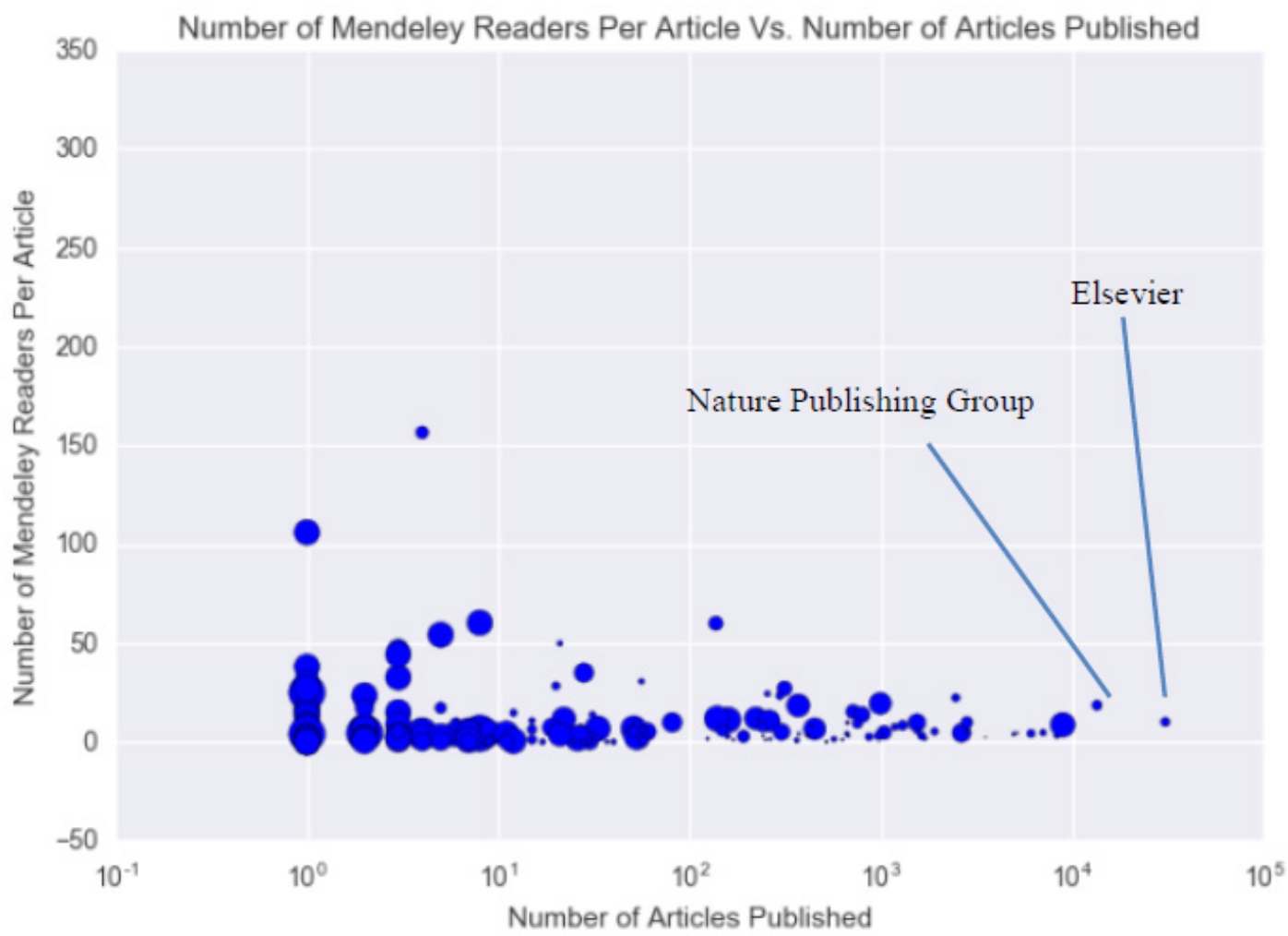

Figure 3.3: Relationship between number of Mendeley readers per article and publisher. The weight is the percentage of articles published in the top 10 subjects with the most views per article. Each plot represents a publisher. The data consists of 1516753 Mendeley readers across 211949 articles. 


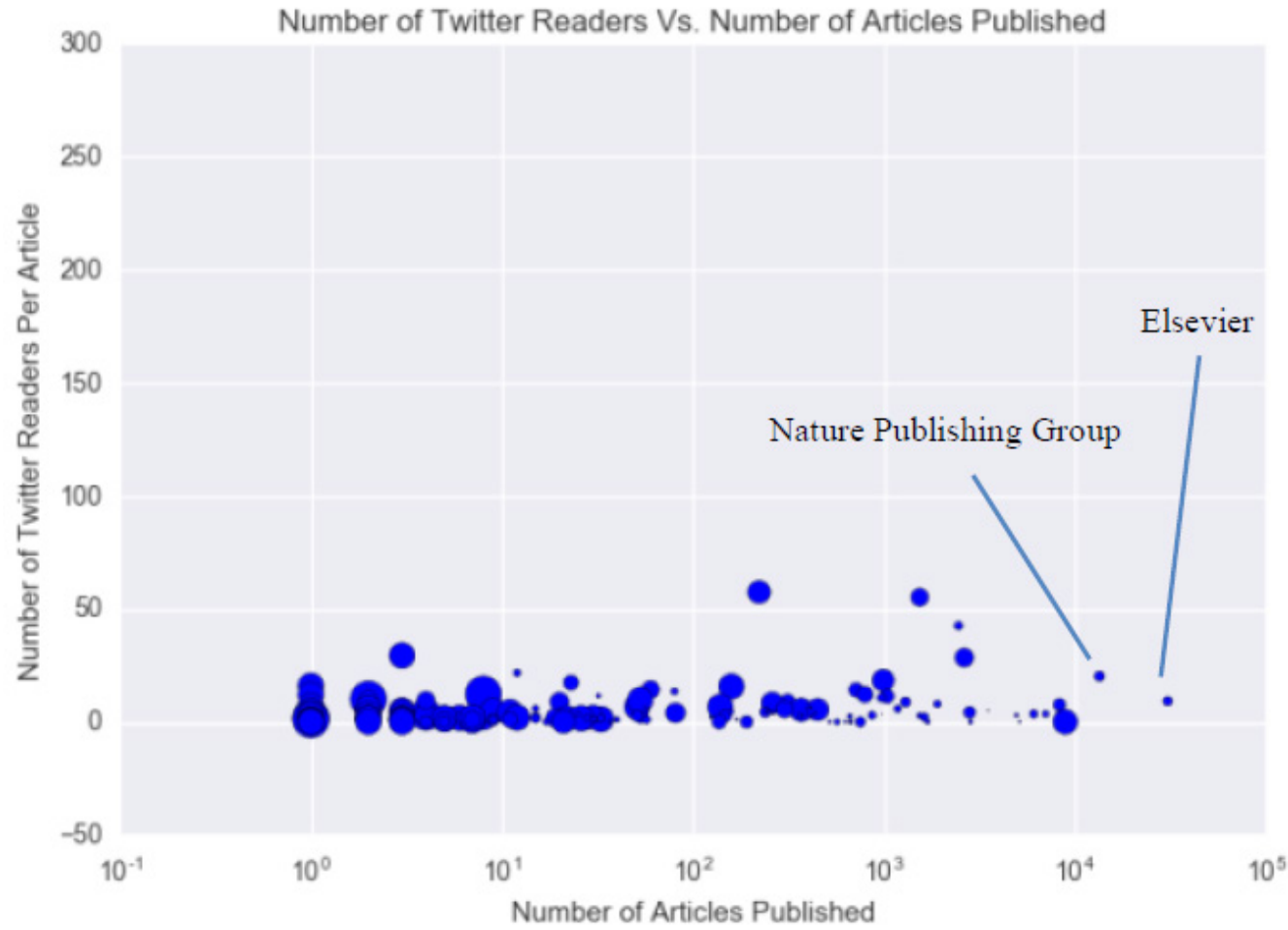

Figure 3.4: Relationship between number of Twitter readers per article and publisher. The weight is the percentage of articles published in the top 10 subjects with the most views per article. Each plot represents a publisher. The data consists of 1537926 Twitter readers across 211949 articles.

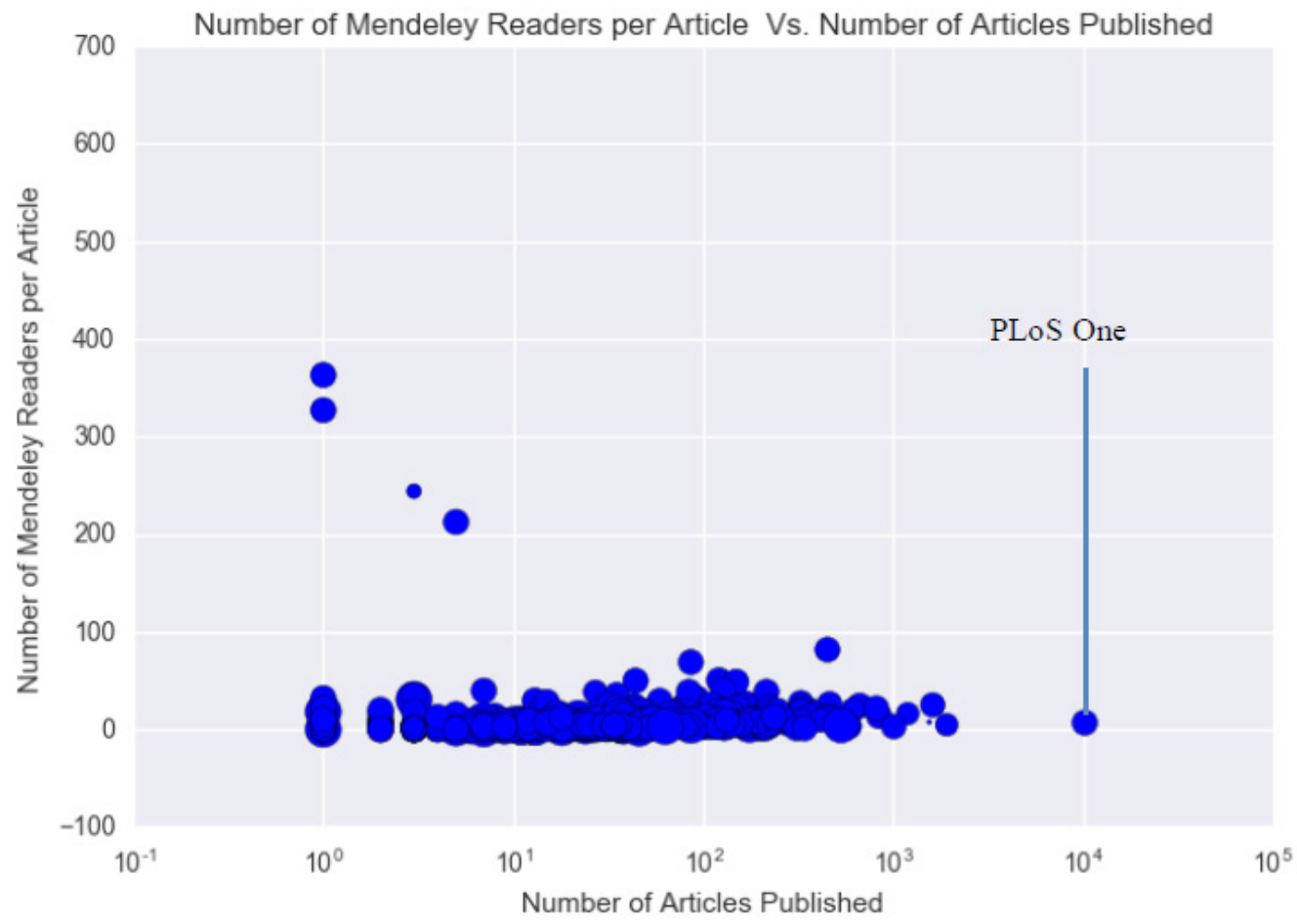

Figure 4.3: Relationship between number of Mendeley readers and journal. The weight is the percentage of articles published in the top 10 subjects with the most views per article. Each plot represents a journal. The data consists of 3225233 Mendeley readers across $\underline{504217 \text { articles. }}$ 
800

Number of Twitter Readers per Article Vs. Number of Articles Published

700

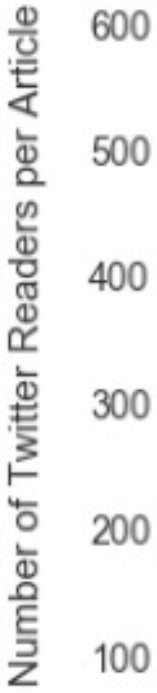

0

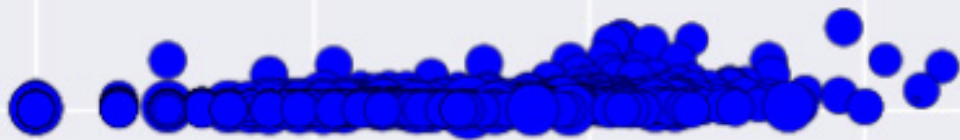

PLoS One

$-100$

$10^{-1}$

$10^{0}$

$10^{1}$

$10^{2}$

$10^{3}$

$10^{4}$

$10^{5}$

\section{Number of Articles Published}

Figure 4.4: Relationship between Twitter readers and journal. The weight is the percentage of articles published in the top 10 subjects with the most views per article. Each plot represents a journal. The data consists of 3699002 Twitter readers across 504217 articles. 